\title{
EFEK LINGKUNGAN KERJA SOSIAL DAN KEPUASAN KERJA PADA LOYALITAS KARYAWAN DALAM INDUSTRI JASA PROPERTI
}

\author{
Farhan Maulana, Sumiyati, Girang Razati \\ Universitas Pendidikan Indonesia \\ farhanmaulana@student.upi.edu \\ sumiyati@upi.edu \\ girangrazati@upi.edu
}

\begin{abstract}
The problem of employee loyalty is still the main concern in the company. It is because there are still many people researching for half a decade that the main components of loyalty include strong beliefs, acceptance of organizational goals, willing to mobilize considerable effort on behalf of the organization and a desire to maintain membership in the organization. Employees who have loyalty to their work will work more effectively and efficiently so that they can optimize their performance and produce good output in the form of products and services. Employee loyalty is a problem that almost happened in every type of company both services and manufacturing in various countries. Starting from the tourism industry, restaurant industry, education industry, health industry, and others. The low employee loyalty toward the company is characterized by decreasing performance, increasing attendance and employee turnover. This occurred to PT. Rezeki Jaya Makmur Sentosa in Ciamis, where the level of employee loyalty has decreased every year, especially in 2014-2018. Surely this is far from the expectations of companies that want their employees to have high loyalty. This study aims to determine (1) the influence of the social work environment on employee loyalty (2) the effect of job satisfaction on employee loyalty (3) the influence of the social work environment and job satisfaction on employee loyalty. This study uses a quantitative method involving 36 respondents using saturated sampling with data collection techniques using questionnaires. The data analysis technique used is multiple linear regression. The results of this study indicate that (1) the influence of the social work environment on employee loyalty partially influences by $70.6 \%$ (2) the effect of job satisfaction on employee loyalty partially influential by $63.3 \%$ (3) the influence of social work environment and job satisfaction on employee loyalty simultaneously influences by $73.5 \%$. This shows that the better the social work environment and job satisfaction, the higher the employee loyalty. This means that if the social work environment and good job satisfaction will be obtained optimal work output, so that employee loyalty can increase properly.
\end{abstract}

Keywords: social work environment, job satisfaction, employee loyalty

Abstrak: Permasalahan loyalitas karyawan masih menjadi perhatian utama dalam perusahaan. Hal ini dikarenakan masih banyak orang meneliti selama setengah dekade bahwa komponen utama loyalitas mencakup keyakinan kuat, penerimaan tujuan organisasi, rela mengerahkan usaha yang cukup atas nama organisasi dan keinginan untuk mempertahanan keanggotaan dalam organisasi. Karyawan yang mempunyai loyalitas pada pekerjaannya akan bekerja lebih efektif dan efesien sehingga bisa mengoptimalkan kinerjanya dan menghasilkan output yang baik berupa produk dan jasa. Loyalitas karyawan menjadi masalah yang hampir terjadi pada setiap jenis perusahaan baik jasa maupun manufaktur diberbagai negara. Mulai dari industri pariwisata, industri restoran, industri pendidikan, industri kesehatan, dan lain-lain. Rendahnya loyalitas karyawan terhadap perusahaan ditandai dengan menurunnya kinerja, meningkatnya absensi dan turnover karyawan. Hal ini terjadi pada PT. Rezeki Jaya Makmur Sentosa di Ciamis dimana tingkat loyalitas karyawan mengalami penurunan pada setiap tahunnya, terutama pada tahun 2014-2018. Tentunya hal ini jauh dari harapan perusahaan yang menginginkan para karyawannya memiliki loyalitas yang tinggi. Penelitian ini bertujuan untuk mengetahui (1) pengaruh lingkungan kerja social terhadap loyalitas karyawan (2) pengaruh kepuasan kerja terhadap loyalitas karyawan (3) pengaruh lingkungan kerja sosial dan kepuasan kerja terhadap loyalitas karyawan. Penelitian ini menggunakan metode kuantitatif dengan melibatkan 36 responden menggunakan sampling jenuh dengan teknik pengumpulan data menggunakan kuisioner. Teknik analisis data yang digunakan adalah regresi linear berganda. Hasil penelitian ini menunjukkan bahwa (1) pengaruh lingkungan kerja sosial terhadap loyalitas karyawan berpengaruh secara parsial sebesar 70,6\% (2) pengaruh kepuasan kerja terhadap loyalitas karyawan berpengaruh secara parsial sebesar 63,3\% (3) pengaruh lingkungan kerja sosial dan kepuasan kerja terhadap loyalitas karyawan berpengaruh secara simultan sebesar 73,5\%. Hal ini menunjukan bahwa semakin baik lingkungan kerja sosial dan kepuasan kerja maka semakin tinggi loyalitas karyawan. Artinya apabila lingkungan kerja sosial dan 
kepuasan kerja baik maka akan diperoleh output kerja yang optimal, sehingga loyalitas karyawan dapat meningkat dengan baik.

Kata kunci: lingkungan kerja sosial, kepuasan kerja, loyalitas karyawan

\section{PENDAHULUAN}

Sejalan dengan era globalisasi dan peningkatan pertumbuhan ekonomi, setiap organisasi laba maupun nirlaba dituntut untuk mempersiapkan diri agar dapat menjadi organisasi yang siap berkompetisi dengan organisasi lain (Bathla, 2017:102). Keterlibatan bagian kepegawaian dalam meningkatkan sumber daya manusia berkualitas secara proaktif dimulai dari perencanaan karir para karyawan perusahaan (Rahayu, Senen, \& Razati, 2018:13). Peranan sumber daya manusia yang ada pada sebuah organisasi semakin penting seiring dengan semakin kompleksnya tugas, tanggung jawab, dan tantangan yang dihadapi organisasi saat ini. Berbagai tekanan, baik secara fisik maupun psikis, sangat mempengaruhi keadaan mental seorang pegawai dalam suatu organisasi (Masharyono, 2015:813). Sumber daya manusia yang berkualitas merupakan faktor dinamis yang mampu menentukan maju atau mundurnya suatu organisasi, sehingga organisasi yang memiliki sumber daya manusia yang handal akan memenangkan persaingan (Masharyono \& Senen, 2015:121). Jika upaya yang harus dilakukan perusahaan untuk mempertahankan sumber daya manusianya dengan cara meningkatkan loyalitas karyawan akan menjaga kelangsungan dan pencapaian tujuan organisasi (Supianto, 2015:119).

Permasalahan loyalitas karyawan masih menjadi perhatian utama dalam perusahaan. Hal ini dikarenakan masih banyak orang meneliti selama setengah dekade dengan intensifikasi di tahun 70-an, 80-an dan 90-an bahwa komponen utama loyalitas mencakup keyakinan kuat, penerimaan tujuan organisasi, rela mengerahkan usaha yang cukup atas nama organisasi dan keinginan untuk mempertahanan keanggotaan dalam organisasi (Ghorbanhosseini, 2013). Pada abad ke-21 bahwa loyalitas karyawan masih menjadi hal yang penting untuk keberhasilan suatu organisasi (Tommy Stefanus, Shelvieana Saputra, 2010:179). Organisasi membutuhkan ide dan pendapat dari karyawan mengenai hal yang menjadi perhatian di tempat kerja (Rahmawati. Sumiyati, Masharyono., 2016:38) Karyawan yang mempunyai loyalitas pada pekerjaannya akan bekerja lebih efektif dan efesien sehingga bisa mengoptiimalkan kinerjanya dan menghasilkan output yang baik berupa produk dan jasa (Haddadi-, Branch, Moghadam-, \& Branch,
2015). Karyawan yang memiliki loyalitas tinggi terhadap organisasinya akan mengoptimalkan semua kemampuannya untuk mendukung kemajuan organisasi (Ismail \& Razak, 2016:32).

Perusahaan tidak dapat bertahan apabila tidak memiliki karyawan yang bekerja dengan baik dan maksimal (Senen \& Masharyono, 2017:68). Masalah loyalitas karyawan merupakan masalah penting yang dihadapi oleh organisasi karena loyalitas merupakan sikap mental yang ditunjukan karyawan pada perusahaan (Hermawan \& Riana, 2010:627). Loyalitas timbul dari diri karyawan itu sendiri, hal tersebut berasal dari kesadaran bahwa antara karyawan dengan perusahaan merupakan dua pihak yang saling membutuhkan. Dengan menggunkan lima dimensi loyalitas yaitu: taat pada peraturan, tanggung jawab pekerjaan, rasa memiliki, hubungan antar pribadi, dan kesukaan terhadap pekerjaan (Saputra, Bagia, \& Yulianthini, 2013:8). Loyalitas karyawan yang rendah disebabkan ketidaknyamanan dan ketidak puasan karyawan terhadap apa yang diberikan organisasi kepadanya hal yang mungkin terjadi adalah banyaknya karyawan yang melakukan absen, sering mangkir kerja, dan bahkan jika ada tawaran kerja ditempat lain dengan fasilitas yang lebih memadai maka tanpa pikir panjang karyawan tersebut akan meninggalkan pekerjaan lamanya (Ahmad, Shukri dan Yusuf Owoyemi, 2012:10), dan menyebabkan karyawan tidak antusias dalam bekerja, sebaliknya jika puas terhadap organisasi, maka akan loyal terhadap organisasinya dan bekrja lebih keras untuk mencapai tujuan organisasi (Meyer, 2014).

Banyak peneliti yang menganggap bahwa loyalitas itu sangat penting dan sangat berpengaruh terhadap produktivitas perusahaan (Surya, 2015:977), loyalitas karyawan juga memiliki pengaruh yang positif terhadap pertumbuhan perusahaan (Antoncic \& Bostjan, 2011). Pengalaman kerja juga menjadi faktor penentu terhadap keahlian dan keterampilan yang dimilikinya, sehingga dapat mempengaruhi loyalitas karyawan (Handoko, 1987:17). Loyalitas karyawan dinilai sejauh mana karyawan mengidentifikasi organisasi dan seberapa tinggi keinginannya untuk terus aktif dalam organisasi (Nongo \& Ikyanyon, 2012). Loyalitas karyawan terhadap organisasi dan proses yang terus menerus sehingga karyawan akan menunjukkan dan mengekspresikan perhatian atau hal 
yang penting terhadap perusahaan (Soeghandi, Sutanto, \& Setiawan, 2013:17), menimbulkan rasa memiliki kepada setiap karyawan yang berada dalam organisasi (Leite, Rodrigues, \& Albuquerque, 2014). Meyer dan Allen (1997) menyatakan bahwa loyalitas yang tinggi akan bekerja dengan penuh dedikasi karena karyawan yang memiliki loyalitas tinggi menganggap bahwa hal yang penting yang harus dicapai adalah pencapaian tugas dalam organisasi. Loyalitas karyawan mencerminkan sejauh mana seorang individu mengidentifikasi dengan organisasi dan tujuannya. (Kreitner \& Kinicki, 2008). Hal tersebut merupakan sikap kerja yang penting karena orang yang loyal diharapkan untuk menampilkan kemauan bekerja lebih keras untuk mencapai tujuan organisasi dan keinginan yang lebih besar untuk tetap dipekerjakan di dalam organisasi (Yousef, 2017).

Memiliki karyawan yang loyal cenderung bertindak lebih produktif terhadap organisasi (Puangyoykeaw \& Nishide, 2015). Karyawan yang loyal akan mencurahkan waktu mereka untuk organisasinya sehingga akan menghasilkan kinerja yang baik (Khuong \& Nhu, 2015). Selain itu, loyalitas karyawan merupakan upaya untuk memahami intensitas dan stabilitas perusahaan. Dapat disimpulkan bahwa karyawan yang sangat loyal terhadap organisasinya cenderung tidak akan meninggalkan organisasi tersebut (Khaleghi, Najafabadi, \& Lashgarara, 2015).

Loyalitas karyawan menjadi masalah yang hampir terjadi pada setiap jenis perusahaan baik jasa maupun manufaktur diberbagai negara (Nugraha, Hidayat, \& Abdurrahman, 2016:192). Mulai dari industri pariwisata, industri restoran, industri pendidikan, industri kesehatan, dan lain-lain. Rendahnya loyalitas karyawan terhadap perusahaan ditandai dengan menurunnya kinerja, meningkatnya absensi dan turnover karyawan (Anugrah, 2014:149). Salah satu industri yang sekarang sedang mengalami rendahnya loyalitas karyawan adalah industri jasa Properti terbukti dari banyaknya turnover karyawan yang diteliti (Wahyuni, \& Zaika, 2014:89) dan menjadi suatu masalah yang harus di kaji dan diselesaikan oleh perusahaan (Wood \& Wilberger, 2015).

Industri properti merupakan perusahaan yang bergerak dalam bidang pembangunan apartemen, perumahan, perkantoran, real estate dan sebagainya. Bisnis properti merupakan salah satu usaha yang dapat dipastikan tidak akan pernah mati karena kebutuhan akan papan atau tempat tinggal. Upaya yang dapat dilakukan perusahan dengan meningkatkan kualitas karyawan untuk meningkatan kualitas pelayanan yang dapat memenuhi harapan pelanggan (Widhiastuti, 2012:26)

Survei yang telah dilakukan oleh PT. CDMI atau perusahaan konsultan terkemuka di Indonesia menyatakan pada tahun 2011 industri properti di Indonesia mengalami pertumbuhan yang pesat, dengan transaksi yang mencapai Rp 301,27 triliun atau naik 24,6\% dibanding pada tahun 2010 sebesar Rp 249,7 triliun, pertumbuhan ini didorong oleh meningkatnya kredit real estate, konstruksi, KPR (Kredit Pemilikan Rumah), dan KPA (Kredit Pemilikan Apartemen). Menurut data yang diperoleh dari Bank Indonesia, pangsa pasar untuk KPR, dan KPA adalah penyumbang terbesar yaitu sebesar $60,62 \%$, disusul kredit konstruksi sebesar 28,86\%, dan kredit real estate sebesar 14,52\% (Wulan, 2015:196). Namun dibalik pertumbuhan tersebut terdapat masalah sumber daya manusia yang disebabkan, budaya oranisasi, kedisiplinan, dan gaya kepemimpinan yang berkaitan dengan loyalitas karyawan, sehingga meningkatnya angka absensi dan turnover karyawan dan berpengaruh terhadap produktivitas kerja (Nalestiyas, 2016). Didalam suatu perusahaan, salah satu faktor penentu dalam loyalitas karyawan adalah turnover, (Soeghandi et al., 2013:20).

Hampir disetiap perusahaan di Indonesia menununjukkan bahwa loyalitas karyawan banyak yang menurun. Menurut survey Global Workforce Study 2012, 27\% dari karyawan saat itu telah merencanakan untuk pindah, dan $42 \%$ dari responden di Indonesia yang sebanyak 1005 karyawan, menyatakan harus meninggalkan perusahaannya untuk meningkatkan karir masa depan. Hal ini disebabkan oleh beberapa faktor. Selain itu, Tower Watson 2014 Talent Management and Reward Study melakukan survey bahwa 36 dari 1637 perusahaan di Indonesia mengalami kesulitan dalam mempertahankan tenaga kerja yang kompeten (Alfiyah, 2017:145).

Industri jasa Properti menghadapi berbagai hambatan dan kendala terutama dalam bidang sumber daya manusia. Salah satunya kemangkiran, Ketepatan absensi waktu jam datang dan jam pulang, jumlah jam kerja selama satu hari, adapun waktu istirahat yang diberikan tidak dilebih-lebihkan sehingga list pekerjaan tidak terbengkalai (Adiwibowo, Sakit, \& Haji, 2016:44). Perkembangan industri Properti di Indonesia masih tertingggal dengan negara-negara lain hal ini disebabkan oleh beberapa faktor yang membuat perilaku karyawan yang kurang maksimal dalam pekerjaan sehingga mengalami hambatan dalam visi organisasi. (Priyono, 2012). Rendahnya tingkat kerja 
karyawan merupakan salah satu ciri loyalitas karyawan (Putra \& Wibawa, 2015).

Tingkat turnover karyawan PT. Rezeki Jaya Makmur Sentosa mengalami fluktuatif. Pada tahun 2014 jumlah karyawan awal tahun yaitu 67 karyawan dan karyawan keluar 4 orang, karyawan masuk 2 orang hingga jumlah akhir karyawan 2014 yaitu 65 orang. Pada tahun 2015 jumlah karyawan awal tahun yaitu 65 karyawan dan karyawan keluar 8 orang, karyawan masuk 3 orang hingga jumlah ahir karyawan 2015 yaitu 70 orang. Pada tahun 2016 jumlah karyawan awal tahun yaitu 70 karyawan dan karyawan keluar 22 orang, karyawan masuk 2 orang hingga jumlah akhir karyawan 2016 yaitu 50 orang. Pada tahun 2017 jumlah karyawan awal tahun yaitu 50 karyawan dan karyawan keluar 11 orang, karyawan masuk 1 orang hinga jumlah akhir tahun 201740 orang. Pada tahun 2018 jumlah karyawan awal tahun yaitu 40 karyawan dan karyawan keluar 5 orang, karyawan masuk 1 orang hingga jumlah akhir tahun 201836 orang. Dapat disimpulkan bahwa data diatas menunjukan data turnover karyawan pada tahun 2014 sampai 2018 mengalami kenaikan. Hal ini diindikasikan bahwa adanya loyalitas karyawan yang rendah pada perusahaan. Hasil data turnover tersebut dapat dihitung presentase tingkat turnover karyawan pada PT. Rezeki Jaya Makmur Sentosa di Ciamis dengan menggunakan rumusan LTO (Labour Turnover).

Permasalahan mengenai loyalitas karyawan menjadi isu penting dimana loyalitas akan selalu dicari oleh setiap menejer saat ini. Berbagai faktor yang mampu meningkatkan loyalitas karyawan diantaranya dengan memperhatikan lingkungan kerja, menawarkan gaji yang tinggi, memberikan pelatihan yang baik, serta mengubah praktik manajemen (Hang \& Valkama, 2016). pentingnya loyalitas karyawan yang berpengaruh pada produktivitas didasarkan pada berbagai faktor yaitu, kepuasan kerja karyawan seperti, kondisi, upah, hubungan kerja dengan rekanrekan, dan pekerjaan organisasi, serta peluang karir, perilaku atasan, penghargaan, hubungan atasanbawahan, gaya manajemen, dan kemandirian (Saifullah \& Sajjad, 2016).

Banyak faktor yang menjadikan seorang karyawan menjadi loyal, diantaranya lingkungan kerja, kompensasi, komunikasi yang efektif, motivasi yang diberikan oleh perusahaan, tempat bekerja yang nyaman, pengembangan karir, pengadaan pelatihan dan pendidikan karyawan, partisipasi kerja, pelaksanaan kesehatan dan keselamatan kerja, serta hubungan antara atasan dan bawahan maupun hubungan karyawan satu dengan yang lainnya
(Susanto, 2010). Lingkungan kerja terbagi menjadi 2, yaitu lingkungan kerja fisik dan lingkungan kerja non fisik (sosial). Lingkungan kerja fisik diidentifikasi sebagai faktor terpenting yang mempengaruhi kepuasan kerja karyawan (Basalamah, 2013) dan merupakan semua keadaan berbentuk fisik yang terdapat di sekitar tempat kerja yang dapat mempengaruhi karyawan baik secara langsung maupun tidak langsung, dimana faktor terbentuknya suatu kondisi lingkungan kerja fisik adalah penerangan/cahaya di tempat kerja, temperature di tempat kerja, kelembaban di tempat kerja, sirkulasi udara yang terdapat di tempat kerja, kebisingan di tempat kerja, dekorasi tempat kerja, keamanan di tempat kerja (Sedarmayanti, 2017:21).

Menurut Sedarmayanti (2017) Lingkungan kerja sosial merupakan keadaan yang terjadi dan berkaitan dengan hubungan kerja, baik hubungan dengan atasan, hubungan dengan sesama rekan kerja maupun pelayanan kepada masyarakat. Sesuatu yang berhubungan dengan segi psikis dari lingkungan kerja disebut sebagai lingkungan kerja sosial (Mondy \& Martocchio, 2016).

Berdasarkan penelitian yang dilakukan (Pandey \& Khare, 2012) diperoleh temuan bahwa faktor lain yang memiliki pengaruh terhadap loyalitas karyawan adalah kepuasan kerja dan komitmen organisasi.

Solusi yang diambil untuk memperhatikan loyalitas karyawan yaitu dengan memperhatikan lingkungan kerja sosial dan kepuasan kerja karyawan. Solusi pertama yaitu lingkungan kerja sosial, penelitian yang dilakukan oleh Stephani, L. A., \& Wibawa (2014) menyatakan bahwa lingkungan kerja dapat mempengaruhi loyalitas karyawan. Solusi kedua yaitu kepuasaan kerja, dalam penelitian yang dilakukan Khuong \& Tien (2013) menyatakan bahwa kepuasan kerja mempengaruhi secara signifikan terhadap loyalitas karyawan.

Direktur utama PT. Rezeki Jaya Makmur Sentosa Bapak Ara memberikan kebijakan demi meningkatkan loyalitas karyawannya dengan cara memperlakukan karyawan sebagai teman sehingga menciptakan lingkungan yang harmonis antara atasan dengan karyawan, maupun antara akryawan dengan karyawan lainnya (10 Oktober 2018).

Direktur utama utama PT. Rezeki Jaya Makmur Sentosa Bapak Ara selalu mengadakan gathering atau liburan bersama tiga bulan sekali untuk bersilaturahmi dan saling mengevaluasi kinerja para karyawan. Disamping itu, gethering tersebut bertujuan supaya para pekerja merasa nyaman telah bekerja sebagai karyawan PT. Rezeki Jaya Makmur 
Sentosa sehingga menimbulkan loyalitas dalam bekerja (10 Oktober 2018).

Kepala lapangan PT. Rezeki Jaya Makmur Sentosa Bapak Eeng selalu memberi motivasi kepada karyawan seminggu sekali. Motivasi tersebut berupa saran dan pujian yang bertujuan untuk memberikan semangat atau gairah kerja kepada karyawan (10 Oktober 2018).

\section{KAJIAN PUSTAKA}

Perilaku organisasi dapat dipelajari dengan tiga faktor penentu, yaitu tingkat individu, kelompok, dan organisasi. Pada tingkat individu, perilaku individu dipengaruhi oleh sikap individu, emosi dan suasana hati individu, kepribadian dan nilai-nilai yang dianut oleh individu, persepsi dan pengambilan keputusan individu, dan motivasi yang dimiliki oleh individu (Robbins \& Judge, 2013:6). Perilaku individu merupakan sesuatu yang dikerjakan seseorang, seperti berbicara dengan manajer, mendengarkan rekan sekerja, menyusun laporan, mengetik memo, menempatkan unit barang ke dalam gudang dan lain sebagainya (Sofyan \& Garniwa, 2007 dalam Mahendra, 2017).

Perilaku organisasi pada tingkat individu salah satunya adalah Kepribadian dan nilai-nilai, yang terdiri dari budaya organisasi, etika kerja, kinerja dan loyalitas (Robbins \& Judge, 2015). Perilaku organisasi secara luas berbicara tentang bagaimana individu berpikir, berinteraksi, dan bertindak dalam struktur sosial formal dan merupakan studi tentang bagaimana organisasi dalam mengembangkan dan memelihara elemen struktur sosial individu yang mempengaruhi perilaku mereka (Secchi \& Neumann, 2016).

Robbins \& Judge (2016) membagi perilaku organisasi menjadi bagian 3 yaitu level individu, level kelompok, dan level organisasi. Level kelompok terdiri atas, 1) dasar dari perilaku kelompok, 2) memahami kerja tim, 3) komunikasi, 4) kepemimpinan, 5) kekuasaan dan politik, 6) konflik dan negosiasi, dan 7) dasar pada struktur organisasi.

Menurut Robbins \& Judge, (2016) bagian struktur memunculkan beberapa struktur elemen penting, salah satunya lingkungan kerja. Lingkungan kerja muncul dari bagian dasar pada struktur organisasi yang berasal dari level kelompok. Lingkungan kerja merupakan salah satu faktor pendukung untuk meningkatkan kinerja di tempat kerja. Menurut Sedarmayanti, (2011: 20) Lingkungan kerja adalah keseluruhan alat perkakas, lingkungan di mana seseorang bekerja, metode kerja, serta pengaturan kerja. Menurut Sunyoto (2012:43) lingkungan kerja merupakan segala sesuatu yang ada di sekitar para pekerja dan yang dapat memengaruhi dirinya dalam menjalankan tugas-tugas yang dibebankan, misalnya kebersihan, kebisingan, penerangan dan lain-lain.

Lingkungan kerja dalam suatu organisasi mempunyai arti penting bagi individu yang bekerja di dalamnya, karena lingkungan ini akan mempengaruhi secara langsung maupun tidak langsung manusia yang ada di dalamnya (Hertanto, 2011). Menurut Rahmawanti, Swasto, \& Prasetya, (2014:2) menyatakan bahwa lingkungan kerja merupakan salah satu komponen terpenting karyawan dalam menyelesaikan pekerjaannya. Karyawan yang memiliki kinerja tidak baik dapat dinilai dari lingkungan kerjanya yang mendukung atau tidak (Robbins \& Judge, 2016). Menurut Sedarmayanti (2017:21) menyatakan bahwa secara garis besar, jenis lingkungan kerja terbagi menjadi dua faktor yaitu faktor lingkungan kerja fisik dan faktor lingkungan kerja sosial.

Menurut Sedarmayanti (2017: 21) lingkungan kerja sosial adalah semua keadaan yang terjadi yang berkaitan dengan hubungan kerja, baik hubungan dengan atasan, hubungan dengan sesama rekan kerja, maupun hubungan dengan bawahan. Menurut Mondy \& Martocchio (2016:361) mengemukakan mengenai lingkungan kerja sosial, " $A$ social work environment is all that happens and is related to work, whether with coworkers, or with subordinates"

Artinya bahwa lingkungan kerja sosial adalah semua keadaan yang terjadi dan berkaitan dengan hubungan kerja, baik atasan maupun dengan sesama rekan kerja, ataupun dengan bawahan. Menurut P. A. A. Mangkunegara (2017: 105) lingkungan kerja sosial adalah semua aspek fisik, psikologis kerja, dan peraturan kerja yang mempengaruhi kepuasan kerja dan pencapaian produktivitas.

Menurut Sedarmayanti (2017: 21) lingkungan kerja sosial memiliki aspek yang harus diperhatikan dalam menjaga keadaan lingkungan disekitar, yaitu: (1) Keadaan yang berkaitan dengan hubungan pada atasan (2) Keadaan yang berkaitan dengan hubungan sesama rekan kerja.

Kepuasan kerja adalah perasaan positif tentang pekerjaan, hasil dari evaluasi karakteristiknya. Seseorang dengan tingkat kepuasan kerja tinggi memegang perasaan positif tentang pekerjaan nya, sementara orang dengan tingkat rendah memegang perasaan negatif (Robbins \& Judge, 2015). Pendapat lain dikemukakan oleh V.G.Kondalkar (2007) yang menyebutkan bahwa kepuasan kerja adalah perbedaan antara jumlah imbalan yang diterima pekerja dan 
jumlah harapan tentang imbalan yang ingin diterima. Ini adalah pe5rbedaan antara keuntungan dalam hal upah, gaji dan harapan. Menurut Veithzal Rivai Zainal (2014: 213) kepuasan kerja adalah perasaan emosional yang positif dari hasil evaluasi seseorang terhadap pekerjaannya dan pengalaman pekerjaannya dengan membandingkan antara apa yang diharapkan dari pekerjaannya dan apa yang benar-benar didapatkannya.

Menurut Stephen P. Robbins dan Timothy A. Judge (2015) terdapat lima dimensi dari Kepuasan kerja, yaitu: (1) Pay (Gaji) (2) Promotion (Promosi) (3) The work itself (Pekerjaan itu sendiri) (4) Supervision (Penyelia) (5) Cowokers (Rekan kerja).

Salah satu karakteristik dari perilaku individu adalah sikap. Individu dalam organisasi dapat membentuk sikap untuk banyak hal (Hellriegel \& Slocum, 2011), namun fokus perhatian perilaku organisasi memiliki jumlah yang sangat terbatas mengenai sikap yang berkaitan dengan kerja. Sikap kerja berisi evaluasi positif atau negatif yang dimiliki oleh karyawan tentang aspek-aspek lingkungan kerja mereka (Robbins \& Judge, 2012). Loyalitas karyawan mnejadi bagian penting pada suatu organisasi karena berpengaruh terhadap pada produktivitas yang didasarkan pada berbagai faktor (Saifullah \& Sajjad, 2016:129). Loyalitas karyawan memiliki sejumlah manfaat bagi perusahaan. Dalam hal keuntungan, karyawan loyal cenderung melakukan lebih baik dari yang diharapkan dengan motivasi tertinggi dan kemampuanya. Karyawan loyal cenderung untuk tetap dengan perusahaan, dan selalu merekomendasikan perusahaan mereka sebagai tempat kerja yang baik (Trung, 2014:5).

Loyalitas merupakan keinginan untuk memproteksi dan menyelamatkan wajah bagi orang lain dan loyalitas sebagai kesetiaan kepada seseorang dengan tidak meninggalkan, membelot atau tidak menghianati yang lain pada waktu diperlukan (Robbins \& Judge, 2013:395). Loyalitas dapat diartikan dengan kesetiaan, pengabdian dan kepercayaan yang diberikan atau ditujukan kepada seseorang atau lembaga, yang di dalamnya terdapat rasa cinta dan tanggung jawab untuk berusaha memberikan pelayanan dan perilaku terbaik (Rasimin, 1988:96). Loyalitas para karyawan dalam suatu organisasi itu mutlak diperlukan demi kesuksesan organisasi itu sendiri (Tommy, 2010:179). Hal ini dibuktikan dengan sikap dan tingkah laku kerja yang positif (Kasmirudin, 2015:837).

Menurut Robbins \& Judge (2016) mengemukakan terdapat tiga dimensi loyalitas karyawan, 1) Loyalitas emosional, 2) Loyalitas moral, 3) Loyalitas berkelanjutan.

\section{METODE PENELITIAN}

Penelitian ini menggunakan pendekatan manajemen sumber daya manusia menganalisis pengaruh disiplin kerja dan keselamatan kesehatan kerja terhadap kinerja karyawan. Independent variabel atau variabel bebas yaitu lingkungan kerja sosial dan kepuasan kerja yang memiliki indikator. Sedangkan masalah penelitian yang menjadi dependent variabel atau variabel terikat adalah loyalitas karyawan yang memiliki dimensi.

Penelitian ini dilakukan di PT. Rezeki Jaya Makmur Sentosa di Ciamis yang berjumlah 36 orang sebagai populasi, pengambilan sampel penelitian mengunakan metode nonprobability sampling yang memberikan peluang yang sama bagi setiap unsur anggota populasi untuk dipilih menjadi sampel kembali (Sugiyono, 2014:156). Pemilihan sampling berdasarkan nonprobability sampling didasarkan pada teknik sensus karena seluruh anggota populasi menjadi sampel sehingga dapat menggambarkan keseluruhan anggota dengan memperoleh data populasi yang diteliti pada PT. Rezeki Jaya Makmur Sentosa di Ciamis.

Menurut Sugiyono (2017:7) jenis penelitian yang digunakan berdasarkan variabel-varibel yang diteliti, maka penelitian yang dilakukan bersifat deskriptif dan verifikatif. Jenis penelitian verifikatif pada dasarnya ingin menguji kebenaran dari suatu hipotesis yang dilaksanakan melalui pengumpulan data dilapangan guna memprediksi dan menjelaskan hubungan variabel satu dengan variabel yang lainnya. Menurut Sugiyono, (2017:8) penelitian verifikatif diartikan sebagai penelitian yang dilakukan terhadap populasi atau sampel tertentu dengan tujuan untuk menguji hipotesis yang telah ditetapkan. Dalam penelitian verifikatif bermaksud untuk menguji pengaruh lingkungan kerja sosial dan kepuasan kerja terhadap loyalitas karyawan.

Berdasarkan jenis penelitian deskriptif dan verifikatif yang dilaksanakan melalui pengumpulan data di lapangan dengan teknik pengumulan data yaitu dengan menggunakan kuisioner, maka metode yang digunakan dalam penelitian ini adalah kuantitatif untuk mendapatkan informasi mengenai lingkungan kerja sosial, kepuasan kerja terhadap loyalitas karyawan.

Penelitian ini menggunakan teknik analisis linear berganda karena penelitian ini menganalisis tiga variabel yaitu lingkungan kerja sosial, kepuasan kerja, dan loyalitas karyawan, selain itu karena tidak ada 
hubungan antara lingkungan kerja social $\left(\mathrm{X}_{1}\right)$, kepuasan kerja $\left(\mathrm{X}_{2}\right)$ maka penelitian ini menggunakan regresi berganda.

\section{HASIL DAN PEMBAHASAN}

Setelah diketahui nilai $\mathrm{R}$, maka koefisien determinasi dapat dihitung menggunakan rumus sebagai berikut:

$$
K D=r^{2} \times 100 \%
$$

Keterangan :

$\mathrm{KD}=$ Koefisien Determinasi

$\mathrm{r}^{2}=$ Koefisien korelasi

\section{TABEL 1}

KOEFISIEN DETERMINASI SECARA PARSIAL

\begin{tabular}{crrrr}
\hline \multicolumn{5}{c}{ Model Summary } \\
\hline Model & R & R Square & $\begin{array}{c}\text { Adjusted R } \\
\text { Square }\end{array}$ & $\begin{array}{l}\text { Std. Error of } \\
\text { the Estimate }\end{array}$ \\
\hline $\begin{array}{l}\text { Lingkungan } \\
\text { Kerja Sosial }\end{array}$ & $.840^{\mathrm{a}}$ & .706 & .698 & 6.053
\end{tabular}

a. Dependent Variabel:Loyalitas Karyawan

b. Predictors (constant) Lingkungan Kerja Sosial

Berdasarkan Tabel 1 dapat diketahu R Square untuk lingkungan kerja sosial sebesar 0,706 maka besarnya pengaruh lingkungan kerja sosial terhadap loyalitas karyawan.

TABEL 2

KOEFISIEN DETERMINASI SECARA

PARSIAL

\begin{tabular}{|c|c|c|c|c|}
\hline \multicolumn{5}{|c|}{ Model Summary } \\
\hline Model & $\mathrm{R}$ & $\begin{array}{c}\mathrm{R} \\
\text { Square }\end{array}$ & $\begin{array}{l}\text { Adjusted R } \\
\text { Square }\end{array}$ & $\begin{array}{l}\text { Std. Error of } \\
\text { the Estimate }\end{array}$ \\
\hline $\begin{array}{l}\text { Kepuasan } \\
\text { Kerja }\end{array}$ & $.795^{\mathrm{a}}$ & 633 & .622 & 6.769 \\
\hline
\end{tabular}

a. Dependent Variabel:Loyalitas Karyawan

b. Predictors (constant) : Kepuasan Kerja

Berdasarkan Tabel 2 dapat diketahu R Square untuk kepuasan kerja sebesar 0,633 maka besarnya pengaruh kepuasan kerja terhadap loyalitas karyawan.

$$
\mathrm{KD}=\mathbf{r}^{2} \times 100 \%
$$

Pengaruh lingkungan kerja sosial terhadap loyalitas karyawan

$$
\begin{aligned}
\mathrm{KD} & =(0,840)^{2} \times 100 \% \\
& =70,6 \%
\end{aligned}
$$

Pengaruh kepuasan kerja terhadap loyalitas karyawan $\mathrm{KD}=(0,795)^{2} \times 100 \%$

$$
=63,3 \%
$$

Adapun besarnya pengaruh secara parsial antara masing-masing variabel pengaruh lingkungan kerja sosial terhadap loyalitas karyawan sebesar $70,6 \%$ dan pengaruh kepuasan kerja terhadap loyalitas karyawan sebesar 63,3\%. Sedangkan sisanya dipengaruhi oleh faktor-faktor lain yang tidak diteliti oleh penulis. Faktor-faktor yang mempengaruhi loyalitas karyawan adalah adanya fasilitas-fasilitas kerja, tunjangan kesejahteraan, suasana kerja serta upah yang diterima dari perusahaan (Martiwi \& Mardalis, 2013) yang menjadi tolak ukur sumber daya manusia yang mempunyai loyalitas.

\section{TABEL 3}

KOEFISIEN DETERMINASI SECARA SIMULTAN

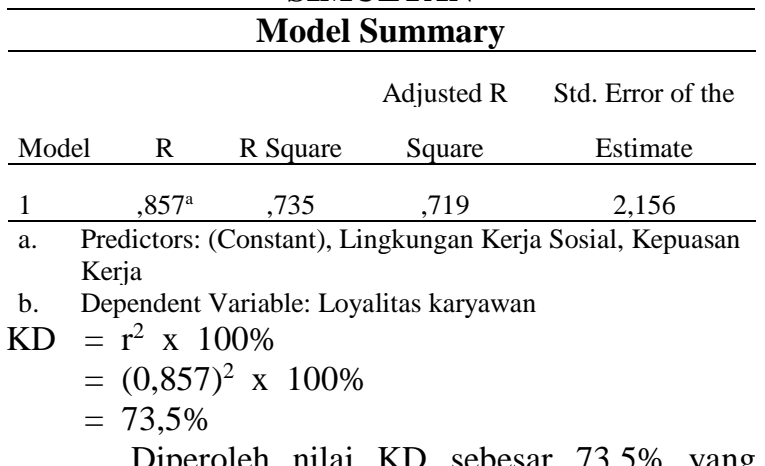
menunjukkan arti bahwa pengaruh lingkungan kerja sosial dan kepuasan kerja memberikan pengaruh simultan (bersama-sama) sebesar $73,5 \%$ terhadap loyalitas karyawan, sedangkan sisanya 26,5\% dipengaruhi oleh faktor lain yang tidak diteliti oleh penulis yaitu faktor-faktor yang mempengaruhi loyalitas karyawan adalah adanya fasilitas-fasilitas kerja, tunjangan kesejahteraan, suasana kerja serta upah yang diterima dari perusahaan (Martiwi \& Mardalis, 2013) yang menjadi tolak ukur sumber daya manusia yang mempunyai loyalitas.

\section{KESIMPULAN DAN SARAN}

Berdasarkan pembahasan teori, hasil penelitian, dan pengujian analisis korelasi multipel yang dilakukan mengenai pengaruh lingkungan kerja sosial dan kepuasan kerja terhadap loyalitas karyawan PT. Rezeki Jaya Makmur Sentosa di Ciamis dapat disimpulkan sebagai berikut:

Berdasarkan penelitian diatas menyatakan bahwa, lingkungan kerja sosial mempunyai pengaruh terhadap loyalitas karyawan. Hal ini menunjukkan bahwa semakin tinggi lingkungan kerja sosial semakin tinggi juga loyalitas karyawan PT. Rezeki Jaya Makmur Sentosa.

Berdasarkan penelitian diatas menyatakan bahwa kepuasan kerja berpengaruh terhadap loyalitas karyawan. Hal ini menunjukkan bahwa semakin tinggi 
kepuasan kerja semakin tinggi loyalitas karyawan PT. Rezeki Jaya Makmur Sentosa.

Berdasarkan penelitian diatas menyatakan bahwa lingkungan kerja sosial dan kepuasan kerja berpengaruh terhadap loyalitas karyawan. Hal ini menunjukan bahwa semakin baik lingkungan kerja sosial dan kepuasan kerja semakin tinggi loyalitas karyawan PT. Rezeki Jaya Makmur Sentosa.

Berdasarkan hasil penelitian, maka penulis menyarankan beberapa hal mengenai lingkungan kerja sosial dan kepuasan kerja meningkatkan loyalitas karyawan, yaitu sebagai berikut:

Hasil penelitian menyatakan bahwa lingkungan krja sosial berpengaruh terhadap loyalitas karyawan, dengan demikian penulis merekomendasikan supaya pimpinan PT. Rezeki Jaya Makmur Sentosa terus membangun dan memperbaiki lingkungan kerja sosial yang efektif untuk meningkatkan kualitas kerja karyawannya. Lingkingan kerja sosial yang baik salah satu cara untuk meningkatkan tingkat loyalitas karyawan, hal ini akan menyebabkan organisasi menjadi lebih baik.

Hasil penelitian ini menyatakan bahwa kepuasan kerja berpengaruh terhadap loyalitas karyawan, dengan demikian penulis merekomendasikan supaya pemimpin terus meningkatkan kepuasan kerja karyawannya, dengan jalan memberikan promosi jabatan yang sesuai pada karyawan dan pihak perusahaan dapat memberikan dan memperhatikan hak-hak pengawas, seperti pemberian bonus, insentif serta kenaikan jabatan agar loyalitas para penyelia meningkat dan menjadikan perusahaan lebih baik lagi.

Hasil penelitian ini menyatakan bahwa lingkungan kerja sosial dan kepuasan kerja secara bersama-sama berpengaruh terhadap loyalitas karyawan. Dengan demikian penulis merekomendasikan agar pemimpin terus meningkatkan lingkungan kerja sosial salah satunya dengan cara atasan bersikap ramah kepada karyawan serta meningkatkan kepuasan kerja dengan cara karyawan menerima gaji yang sesuai dengan jabatan agar loyalitas karyawan dapat meningkat

\section{DAFTAR PUSTAKA}

Amstrong, Michael. (2016). Human Resource Management Practice. Great Britian and The United States: Kogan Page Limited

Dessler, Gary. (2011). Manajemen Sumber Daya Manusia: edisi Kesepuluh jilid Satu. Jakarta Barat: PT Indeks.

Gibson, James L, John M. Ivancevich, James H. Donnell. Jr, Robert Konopaske. (2012). Organizations: Behavior, Structure,
Processes, Fourteen Edition. New York: McGraw-Hill, Inc.

Gomez-Mejia, Luis R and David B. Balkin and Robert L. Cardy. 2012. Managing Human Resources. Prentice Hall: Pearson Education, Inc.

Mondy, R. W., \& Martocchio, J. J. (2016). Human Resource Management (Fourteenth). England: Pearson Education Limited.

Rivai, Veitzhal. (2014: 3). Manajemen Sumber Daya Manusia Dari Teori Ke Prakter. Rajawali Pers: Jakarta.

Sedermayanti (2017). Manajemen Strategi. Refika Aditama: Jakarta.

Sugiyono, A. (2009). Manajemen Keuangan untuk Praktisi Keuangan. Jakarta: Grasindo.

Sugiyono. (2017). Metode Penelitian Pendidikan (Pendekatan Kuantitatif, Kualitatif, dan R\&D). Bandung: Alfabeta.

Sutrisno, Edy. 2017. Manajemen Sumber Daya Manusia, Cetakan Kelima. Yogyakarta: Prenada Media

Wibowo, 2017. Manajemen Sumber Daya Manusia, Edisi Revisi. Jawa Timur: CV. R.A.De.Rozarie

Widodo (2015). Manajemen Pengembangan Sumber Daya Manusia. Pustaka Pelajar: Jakarta.

Adiwibowo, A. S., Sakit, R., \& Haji, A. (2016). Kepemimpinan dan loyalitas terhadap kinerja karyawan rsj menur surabaya, 41-58.

Alfiyah, S. E. (2017). Motivasi kerja, loyalitas, dan kualitas karyawan terhadap kinerja karyawan pt. varia usaha gresik, 8(2), 144-155.

Antoncic, J. A., \& Bostjan, A. (2011). Employee Loyalty And Its Impact On Firm Growth, 15(1), 81-88.

Anugrah. (2014). Hubungan Antara Kepuasan Kerja Dengan Komitmen Organisasional Karyawan Di Pt Sari Warna Asli Garment-Surakarta. Jupe UNS, 2(2), 148-158.

Basalamah, A. (2013). Pengaruh Kepuasan Kerja Terhadap Loyalitas Staf Reception Pada Hotel X Di Madiun Jawa Timur, 493-501.

Fu, W., \& Deshpande, S. P. (2014). The Impact of Caring Climate, Job Satisfaction, and Organizational Commitment on Job Performance of Employees in a China's Insurance Company. Journal of Business Ethics, 124(2), 339-349. https://doi.org/10.1007/s10551-013-1876-y

Ghorbanhosseini, M. (2013). the Effect of Organizational Culture, Teamwork and Organizational Development on Organizational 
Commitment: the Mediating Role of Human Capital. Utjecaj Organizacijske Kulture, Timskog Rada i Razvoja Organizacije Na Predani Rad u Organizaciji: Posrednička Uloga Ljudskog Kapitala., 20(6), 1019-1025. https://doi.org/10.1016/1053-4822(91)90011-Z

Haddadi-, E., Branch, Z., Moghadam-, K. A., \& Branch, Z. (2015). Evaluation and analysis of psychological empowerment and their impact on organizational commitment. International Research Journal of Applied and Basic Sciences, (3), 60-65.

Hang, N.T. Le \& Valkama, P. (2016). University of Economics Ho Chi Minh City AN Investigation Of Factors Affecting Employee Satisfaction And Loyalty In The Fire Fighting And Prevention Police Of Ho Chi Minh City Supervisor: Prof . Pekka Valkama Student: Nguyen Thi Le Hang Student number.

Hermawan, I. K. A., \& Riana, I. G. (2010). Analisis Faktor-Faktor Yang Menentukan Loyalitas Karyawan Pada Pt . Inti Buana Permai Denpasar Bali. Fakultas Ekonomi Universitas Udayana (Unud), Bali, Indonesia, 624-643.

Hertanto, E. (2011). Pengaruh Stressor, Kepuasan Kerja dan Lingkungan Kerja Terhadap Kinerja Karyawan PT. Putera Dharma Industri Pulogadung Jakarta Timur.

Ismail, A., \& Razak, M. R. . (2016). The effect of job satisfaction on organizational commitment. Management \& Marketing, 14(1), 25-40. https://doi.org/10.13140/RG.2.1.4082.3280

Joseph, J. M., \& Mondy, R. W. (2016). Human Resource Management (Fourteenth). London: Pearson Education.

Kasmirudin. (2015). Analisis Loyalitas Kerja Karyawan Hotel Rmg(Sebagai Suatu Formulasi Peningkatan Loyalitas Karyawan), (November), $1-11$.

Khaleghi, A., Najafabadi, M. O., \& Lashgarara, F. (2015). Effective Factors on Job Stress from Experts 'Perception; a Case Study in Iranian Agriculture Engineering Organization, 5(1), 94 99.

Khuong, M. N., \& Nhu, N. V. Q. (2015). The Effects of Ethical Leadership and Organizational Culture towards Employees' Sociability and Commitment-A Study of Tourism Sector in Ho Chi Minh City, Vietnam. Journal of Advanced Management Science, 3(4), 329-336. https://doi.org/10.12720/joams.3.4.329-336

Khuong, M. N., \& Tien, B. D. (2013). Factors influencing employee loyalty directly and indirectly through job satisfaction - A study of banking sector in Ho Chi Minh City, 1(4), 8195.

Leite, N. R. P., Rodrigues, A. C. de A., \& Albuquerque, L. G. de. (2014). Organizational commitment and job satisfaction: what are the potential relationships? Brazilian Administration Review - BAR, 11(4), 476-495. https://doi.org/10.1590/1807-7692bar2014276

Mangkunegara, P. A. A. . (2017). Manajemen Sumber Daya Manusia Perusahaan. Bandung: Remaja Rosdakarya.

Masharyono, M. (2015). Pengaruh Job Characteristic Terhadap Semangat Kerja Pegawai. Jurnal Riset Akuntansi Dan Keuangan Program Studi Akuntansi Fakultas Pendidikan Ekonomi Dan Bisnis Universitas Pendidikan Indonesia, 3(3), 813-830.

https://doi.org/http://dx.doi.org/10.17509/jrak.v 3i3.6622

Masharyono, \& Senen, S. H. (2015). Characteristics dalam Mendukung Universitas Pendidikan Indonesia Mencapai Leading And Outstanding (Job Performance Analysis Temporary Employee Administrative with Competence and Job Characteristics in Supporting Universitas Pendidikan Indonesia Leading an. Fokus Ekonomi, 10(2), 119-137.

Meyer, J. P. (2014). Orga- nizational Commitment Questionnaire.

Nalestiyas, A. P. (2016). Peran Keterikatan Karyawan Dalam Memediasi Pengaruh Antara Budaya Organisasi, Gaya Kepemimpinan Dan Loyalitas Karyawan Pada Pt. Kantaraya Utama.

Nongo, E. S., \& Ikyanyon, D. N. (2012). The Influence of Corporate Culture on Employee Commitment to the Organization. International Journal of Business and Management, 7(22), 21-28. https://doi.org/10.5539/ijbm.v7n22p21

Nugraha, R. A., Hidayat, A. R., \& Abdurrahman, D. (n.d.). Pengaruh Kompensasi Kerja dan Komitmen Organisasi terhadap Turnover Intention Karyawan di BMT Itqan The Effect of Employment Compensation and Organizational Commitment Againts Employee Turnover Intention at BMT Itqan Pendahuluan menjadi lebih kompetitif ., 05, 189-195.

Pandey, Chetna \& Khare, R. (2012). IMPACT OF JOB SATISFACTION AND ORGANIZATIONAL, $1(8)$.

Puangyoykeaw, K., \& Nishide, Y. (2015). Organizational Commitment and Turnover Intention in Low-Skilled Immigrant Workers in 
Thailand: An Empirical Assessment of Need Satisfaction, Job Satisfaction and Overall Life Satisfaction Factors. International Journal of Business and Management, 10(5), 98-113. https://doi.org/10.5539/ijbm.v10n5p98

Putra, I. G. A. G. E. M., \& Wibawa, I. M. A. (2015). Intention Dengan Komitmen Organisasi Sebagai Variabel Intervening Pada Pt . Autobagus Rent Car Bali. E-Jurnal Manajemen Unud, 4(4), 1100-1118.

Rahayu, M. A., Senen, S. H., \& Razati, G. (2018). Gambaran Lingkungan, Kepuasan Kerja Dan Loyalitas Karyawan El Royale Hotel Bandung, 3(1), 11-20.

Rahmawanti, N. P., Swasto, B., \& Prasetya, A. (2014). Pengaruh Lingkungan Kerja Terhadap Kinerja Karyawan (Studi pada Karyawan Kantor Pelayanan Pajak Pratama Malang Utara). Jurnal Administrasi Bisnis (JAB)|, 8(2), 1-9.

Rahmawati. Sumiyati. Masharyono. (2016). Leader Member Exchange Dan Kepribadian Untuk Meningkatkan Employee Voice Kopontren DT. Strategic Jurnal Pendidikan Manajemen Bisnis, 11(20), 38-44.

Robbins, S. P., \& Judge, T. A. (2016). Organizational Behavior (17th ed.). United States: Pearson Education.

Robbins, S. P., \& Judge, T. A. (2017). Organizational Behavior, 739 . Retrieved from www.pearsonglobaleditions.com

Saifullah, A., \& Sajjad, P. S. (2016). intra Organizational Factors that impact Employee 's Loyalty, 10(1), 2016.

Saputra, A. T., Bagia, I. W., \& Yulianthini, N. N. (2013). Pengaruh Kepuasan Kerja dan Loyalitas Karyawan terhadap Kinerja Karyawan. EJournal Bisma Universitas Pendidikan Ganesha, 4(1), 1-8. Retrieved from http://ejournal.undiksha.ac.id/index.php/JJM/ar ticle/view/6730

Secchi, D., \& Neumann, M. (2016). Agent-Based Simulation of Organizational Behavior. https://doi.org/10.1007/978-3-319-18153-0_16

Sedarmayanti. (2011). Manajemen Sumber Daya Manusia, Reformasi Birokrasi dan Manajemen Pegawai Negeri Sipil (Kelima). Bandung: PT Rafika Aditama.

Senen, S. H. (2017). Employee Performance Assessment System Design Based on Competence. Innovation of Vacational Technology Education, 2(8), 68-70.

Soeghandi, V. M., Sutanto, E. M., \& Setiawan, R. (2013). Pengaruh kepuasan kerja dan loyalitas kerja terhadap organizational citizenship behavior, 1(1).

Stephani, L. A., \& Wibawa, I. M. A. (2014). Pada Loyalitas Karyawan Berdasarkan, (1), 30783095.

Stephen P. Robbins, T. A. J. (2015). Perilaku Organisasi (Edisi 16). Jakarta: Salemba Empat.

Sugiyono. (2012). Metode Penelitian Kuantutatif Kualitatif dan $R \& D$. Bandung: Alfabeta.

Sugiyono. (2014). Metode Penelitian Manajemen. Bandung: Alfabeta.

Sunyoto, D. (2012). Teori, Kuesioner, Dan Analisis Data Sumber Daya Manusia (Praktek Penelitian). Yogyakarta: Center For Academic Publishing Service.

Supianto, Y. (2015). Pengaruh Kompensasi, Kompetensi dan Komitmen Organisasional Terhadap Kepuasan dan Kinerja. Jurnal Economia, 11(2).

Surya, I. B. K. (2015). Pengaruh Pengalaman Kerja Dan Kepemimpinan Transformasional Terhadap Loyalitas Karyawan, 4(4), 930-942.

Tommy Stefanus, Shelvieana Saputra, \& E. M. S. (2010). Analisis Pemotivasian dan Loyalitas Karyawan Bagian Pemasaran PT . Palma Abadi Sentosa di Palangka Raya, 1(2), 176-193.

V.G.Kondalkar. (2007). Organizational Behaviour. New Delhi: New Age International Publishers. https://doi.org/10.4324/9780203765326

Veithzal Rivai Zainal. (2014). Kepemimpinan dan Perilaku Organisasi. Jakarta: PT. RajaGrafindo Persada.

Wahyuni, A. S., Zaika, Y., Anwar, R., Brawijaya, U., \& Timur, J. (2014). Analisis Faktor-Faktor Yang Mempengaruhi Turnover Intention ( Keinginan Berpindah ) Karyawan, 8(2), 89-95.

Widhiastuti, H. (2012). Membangun Loyalitas SDM.

Wood, V. R., \& Wilberger, J. S. (2015). Globalization, Cultural Diversity and Organizational Commitment: Theoretical Underpinnings. World Journal of Management, 6(2), 154-171.

Wulan, S. (2015). Manajemen Dan Bisnis, 5(2).

Yousef, D. A. (2017). Organizational Commitment, Job Satisfaction and Attitudes toward Organizational Change: A Study in the Local Government. International Journal of Public Administration, $\quad 40(1), \quad 77-88$. https://doi.org/10.1080/01900692.2015.107221 7 